Pathare PB, Berry TM, Opara UL. Experimental investigation of compression strength of ventilated corrugated citrus packaging. Packaging Research 2017, 2(1), 22-27.

DOI link

https://doi.org/10.1515/pacres-2017-0003

ePrints link

http://eprint.ncl.ac.uk/238828

Date deposited

$23 / 04 / 2018$

Copyright

(c) 2018.

Licence

This work is licensed under a

Creative Commons Attribution-NonCommercial-NoDerivatives 4.0 International licence

$$
\text { (c) } \underset{\mathrm{BY}}{(} \mathrm{NC}_{\mathrm{ND}}
$$




\section{Experimental investigation of compression strength of ventilated corrugated citrus packaging}

https://doi.org/10.1515/pacres-2017-0003

Received Mar 24, 2017; accepted Jun 12, 2017

\begin{abstract}
Ventilated corrugated paperboard packaging is the most widely type of packaging used in postharvest handling and transportation of fresh horticultural produce, during which the package may be exposed to different environmental conditions. Ventilated packages should be designed in such a way that they can provide uniform airflow distribution without compromising mechanical integrity. This study investigated the effects of different storage conditions $\left(-0.5^{\circ} \mathrm{C}\right.$ at $90 \% \mathrm{RH} ; 4^{\circ} \mathrm{C}$ at $90 \% \mathrm{RH}, 10^{\circ} \mathrm{C}$ at $90 \% \mathrm{RH}$ ) on the mechanical performance of two types of ventilated packaging ['Supervent' ( $4.7 \%$ vent area) and 'Standard' (3.1\% vent area)] used for handling citrus fruit. The effects of storage condition on moisture content of package was also studied. Standard packaging showed higher compression strength than supervent packaging, presumably due to less vent area on the package. Maximum compressive strength reduction was found at storage temperature $4^{\circ} \mathrm{C}$ for both packages. The compressive strength of both packages decreased with increase in moisture content.
\end{abstract}

Keywords: Corrugated packaging; Compression strength; Vent area; Horticultural Produce

\footnotetext{
^Corresponding Author: Umezuruike Linus Opara: Postharvest Technology Research Laboratory, South African Research Chair in Postharvest Technology, Department of Horticultural Sciences, Faculty of AgriSciences, Stellenbosch University, South Africa; Postharvest Technology Research Laboratory, South African Research Chair in Postharvest Technology, Department of Food Science, Faculty of AgriSciences, Stellenbosch University, South Africa; Email: opara@sun.ac.za; umunam@yahoo.co.uk; Tel.: +27 21808 4064; Fax: +27 218083743

Pankaj B. Pathare: Postharvest Technology Research Laboratory, South African Research Chair in Postharvest Technology, Department of Horticultural Sciences, Faculty of AgriSciences, Stellenbosch University, South Africa; Postharvest Technology Research Laboratory, South African Research Chair in Postharvest Technology, Department of Food Science, Faculty of AgriSciences, Stellenbosch University, South Africa; Sir Joseph Swan Centre for Energy Research, Newcastle University, Newcastle upon Tyne, United King dom
}

\section{Introduction}

Packaging fresh fruit and vegetables is an important step in the long and complicated journey from the grower to consumer. Ventilated packaging is one of the most important technological innovations to promote rapid, uniform and efficient cooling process of horticultural produce [1, 2]. Recently, Pathare et al. [3] reported a comprehensive review on ventilated packaging systems which showed that the recommended vent area differ considerably. Venting, which is necessary for precooling and proper air circulation, also has the effect of decreasing mechanical strength of the package. Strength and ventilation capability are heavily dependent on the geometric location, sizes and shapes of the ventilation holes. Singh et al. [4] found that box strength decreased with larger holes and holes located further from the centre of the box panel.

Corrugated paperboard strength is an important requirement to protect produce against damage during storage and transport $[5,6]$. Box compression strength (BCT) constitutes a general measure of the performance potential of a corrugated board package [7]. The compression strength of the ventilated corrugated package was significantly influenced by package design and environmental conditions [8]. Mechanical properties of corrugated paperboard are susceptible to temperature and relative humidity variation during the manufacturing, storage and distribution [9]. As relative humidity changes cause the transfer of the moisture of paperboard, and subsequently affects the packaging properties [9]. Exposure to high humidity is one of the most important environmental factor that reduces the strength of paper packaging [10]. Paper fibres may absorb moisture from or release to the surrounding environment as the $\mathrm{RH}$ of the environment fluctuates. Furthermore, when paper material absorbs moisture, the water content increases significantly and the bond of the cellulose fibre of the paper material breaks, greatly affect-

Tarl M. Berry: Postharvest Technology Research Laboratory, South African Research Chair in Postharvest Technology, Department of Horticultural Sciences, Faculty of AgriSciences, Stellenbosch University, South Africa

2 Open Access. (c) 2017 P. B. Pathare et al., published by De Gruyter Open. Attribution-NonCommercial-NoDerivatives 4.0 License 


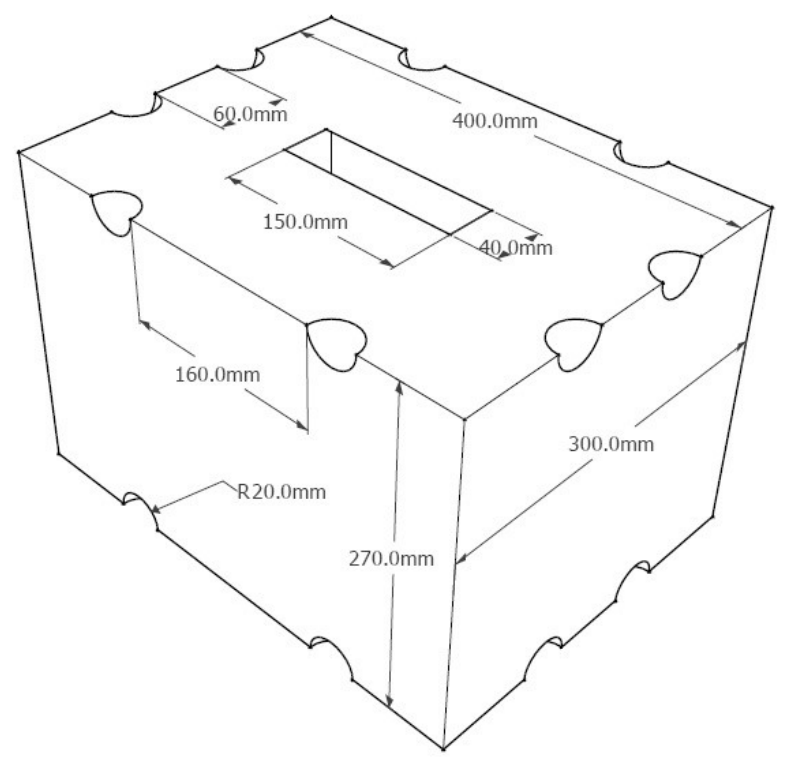

(a) Supervent package

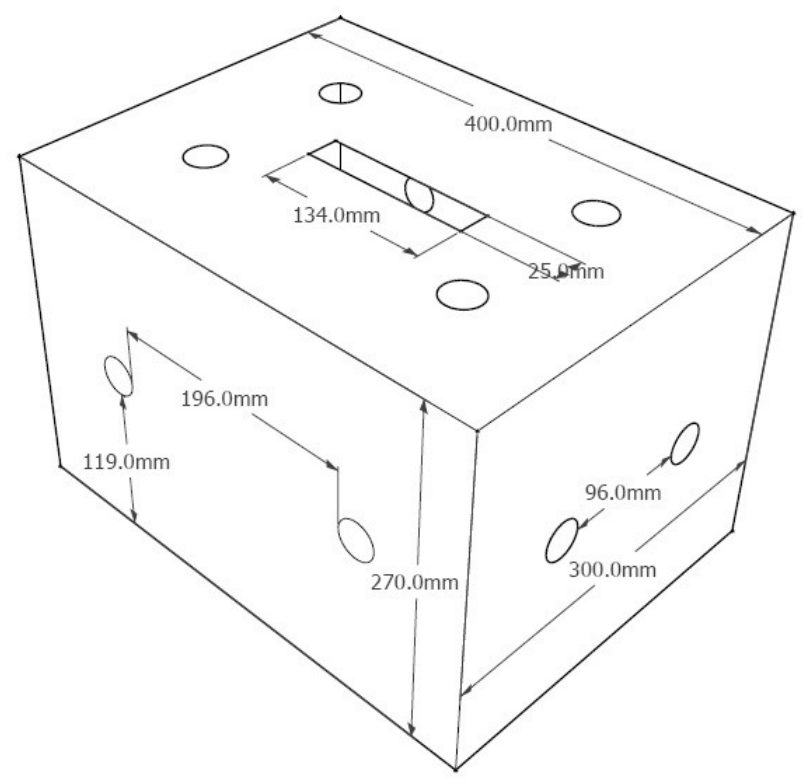

(b) Standard package

Figure 1: Ventilated corrugated packaging designs studied

ing the mechanical properties [11-13]. Wetness due to high humidity storage reduces the compression strength corrugated paperboard packaging. The strength reduction can lead to packaging collapse and causes further mechanical damage to produce [14]. Box strength requirement and influence of environmental exposure on the package performance must be considered in designing corrugated package for long term storage of fresh horticultural produce [15].
Fresh horticultural produce is subject to palletizing, cold storage and transportation, and hence the package must exhibit high stacking strength, resistance to moisture and withstand frequent changes in humidity [16]. Moisture is especially important when loading occurs over long times as corrugated packaging sometimes fails during transportation and storage. Corrugated package compression strength reduced with increase in moisture content [17]. Ventilated corrugated package should be designed to withstand mechanical stresses during distribution process. For engineering purposes, therefore, it is important to be able to determine the allowable load that does not cause collapse within the foreseen storage time. Homogeneity of the cooling process is largely influenced by the structure and design of the packaging system [18]. Thus, until recently, finding an acceptable compromise between the optimal vent area and the mechanical integrity of the container has been considered as a big challenge. Little venting does not affect the structure resistance but restricts the airflow and generates cooling heterogeneity; too much venting weakens the carton container [3]. A number of researchers have studied airflow as well as the heat and mass transfer characteristics of ventilated packing systems [19-23], however very limited studies found on mechanical integrity of ventilated corrugated packaging. In this study, the mechanical performance 'Standard' and 'Supervent' corrugated packaging designs used in the citrus fruit industry was investigated under compression load at different storage conditions.

\section{Material and methods}

Two types of ventilated corrugated citrus packages, 'Standard and Supervent', were used in this study (Figure 1). The packages had dimensions of $400(\mathrm{~L}) \times 300(\mathrm{~W}) \times 270$ (H) $\mathrm{mm}$ and carrying capacity of $15 \mathrm{~kg}$. The outer component of the package consists of a flute construction of type "C" ( $4 \mathrm{~mm}$ thickness), whereas the inner component consists of a double "B" and "C" flute construction $(6 \mathrm{~mm}$ thickness) for both type of packaging. The only difference between the two packages is the number, size and positioning of the different vent holes: the 'Standard' container has two circular vents on each side, at half height while the 'Supervent' container has half-circular vent holes, located at the top and bottom of the sides. Vent opening areas of the package designs is shown in Table 1. 
Table 1: Vent area (\%) of two packaging designs used for citrus

\begin{tabular}{cccccc}
\hline $\begin{array}{c}\text { Package } \\
\text { Type }\end{array}$ & $\begin{array}{c}\text { Length } \\
\text { side }\end{array}$ & $\begin{array}{c}\text { Width } \\
\text { side }\end{array}$ & Top & Bottom & Total \\
\hline Standard & $1.3 \%$ & $1.7 \%$ & $6.3 \%$ & $4.9 \%$ & $3.1 \%$ \\
Supervent & $2.3 \%$ & $3.1 \%$ & $8.1 \%$ & $7.5 \%$ & $4.7 \%$ \\
\hline
\end{tabular}

\subsection{Compression test}

Both package designs were conditioned at $23 \pm 1^{\circ} \mathrm{C}$ and $50 \%$ relative humidity for 48 hours prior to testing in accordance with ASTM D4332. A samples of five boxes of each package design was placed in storage rooms under different storage temperatures $\left(-0.5,4\right.$ and $\left.10^{\circ} \mathrm{C}, 90 \% \mathrm{RH}\right)$ for $48 \mathrm{~h}$. All compression tests were conducted using a Lansmont squeezer compression test system (Lansmont Corporation, Monterey, CA, USA). A preload of $222 \mathrm{~N}$ was applied prior to observing the compression strength values $[8,24]$. The floating-platen mode of the compression tester was used to conduct all testing at a speed of 12.7 $\pm 2.5 \mathrm{~mm} \mathrm{~min}^{-1}$ until failure was observed. Box compression test (BCT) is a pure top-to-bottom compression load test between flat parallel steel plates that is carried out on an empty sealed corrugated board box using a constant deformation speed. The compressive load and crosshead displacement are recorded continuously until collapse occurs. Each test was conducted in five replicates. The moisture content was determined by the method of oven drying at temperature of $105^{\circ} \mathrm{C}$ (TAPPI T412) to constant weight.

Statistical tests used SAS 9.2 software (SAS, North Carolina, USA). Bonferroni comparisons were completed on the replicated data $(\alpha=0.05)$ in all tests.

\section{Result and discussion}

\subsection{Comparison of package design}

Mean compression strength of both package designs at different storage conditions is shown in Table 2. 'Standard' packaging design had the highest compression strength $(9244.3 \mathrm{~N})$ at standard testing condition. The lower (13.8\%) compression strength of 'Supervent' package design less may be attributed to the higher (34\%) ventilation area. 'Supervent' packaging showed the strength reduction between 5.8 to $6.6 \%$ at different storage temperature compared to the standard packaging (Figure 2). This result clearly shows the impact of ventilation on corrugated packaging strength. Singh et al. [4] also observed that there is a linear relationship between the loss of strength

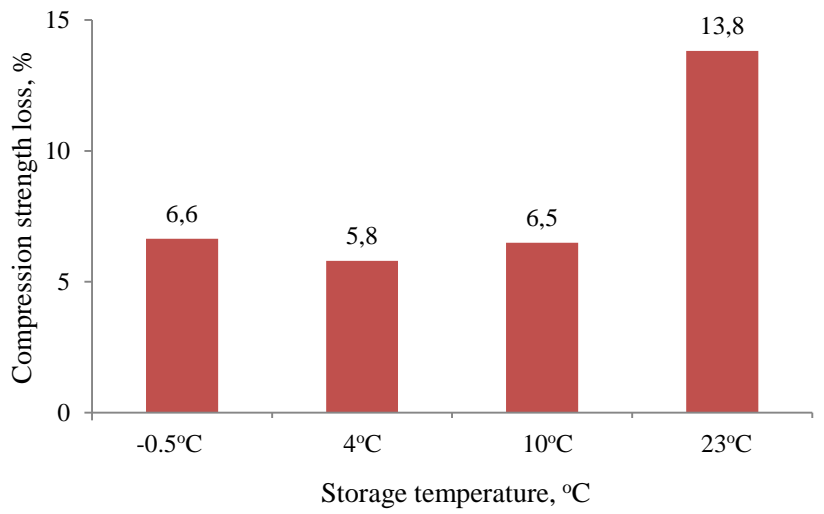

Figure 2: 'Supervent' package compression strength reduction compared to 'Standard' package at different storage temperatures

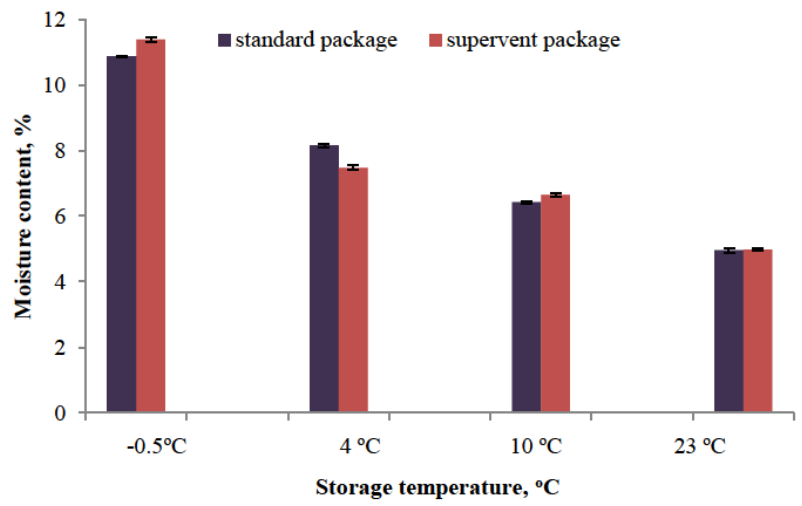

Figure 3: Effect of different storage conditions on moisture content of packaging material

and total vent area. Jinkarn, Boonchu, and Bao-Ban [25] studied the effect different vent area $(1 \%, 2 \%, 3 \%$ and $4 \%$ ) on compression strength for seven different shape of corrugated board panels and found that the compression strength increased when the vent area was reduced.

For both package designs, the average moisture content of the package material was $4.96 \%$ when storage at standard testing conditions $\left(23^{\circ} \mathrm{C}\right.$ and $\left.50 \% \mathrm{RH}\right)$. The influence of storage conditions on moisture content is shown in Figure 3, as expected the increase in storage temperature decrease the moisture content of package. Storage conditions showed the significant effect $(\mathrm{P}<0.05)$ on moisture content for both packages. During that time, the moisture content increased by $54.4 \%$ (Standard) and 56.3\% (Supervent). As increasing temperature will reduce the moisture content of paperboard as high temperature can cause the water evaporation of fibre and reduces the moisture content. Wang et al. [26] also found the moisture content of paper honeycomb sandwich panel decreased as the rise in temperature for the same relative humidity. 
Table 2: Effect of storage conditions on box compression strength and deformation

\begin{tabular}{ccccc}
\hline \multirow{2}{*}{ Storage condition } & \multicolumn{2}{c}{ 'Supervent' package } & \multicolumn{2}{c}{ 'Standard' package } \\
\cline { 2 - 5 } & $\begin{array}{c}\text { Compression } \\
\text { strength, } \mathrm{N}\end{array}$ & Deformation, $\mathrm{cm}$ & $\begin{array}{c}\text { Compression } \\
\text { strength, } \mathrm{N}\end{array}$ & Deformation, $\mathrm{cm}$ \\
\hline$-0.5^{\circ} \mathrm{C} / 90 \% \mathrm{RH}$ & $5337 \pm 119$ & $1.27 \pm 0.06$ & $5717 \pm 154$ & $1.49 \pm 0.02$ \\
$4^{\circ} \mathrm{C} / 90 \% \mathrm{RH}$ & $4791 \pm 170$ & $1.37 \pm 0.07$ & $5086 \pm 44$ & $1.39 \pm 0.06$ \\
$10^{\circ} \mathrm{C} / 90 \% \mathrm{RH}$ & $6417 \pm 28$ & $1.35 \pm 0.04$ & $6862 \pm 222$ & $1.49 \pm 0.04$ \\
$23^{\circ} \mathrm{C} / 50 \% \mathrm{RH}$ & $7969 \pm 151$ & $1.41 \pm 0.03$ & $9244 \pm 219$ & $1.41 \pm 0.07$ \\
\hline
\end{tabular}

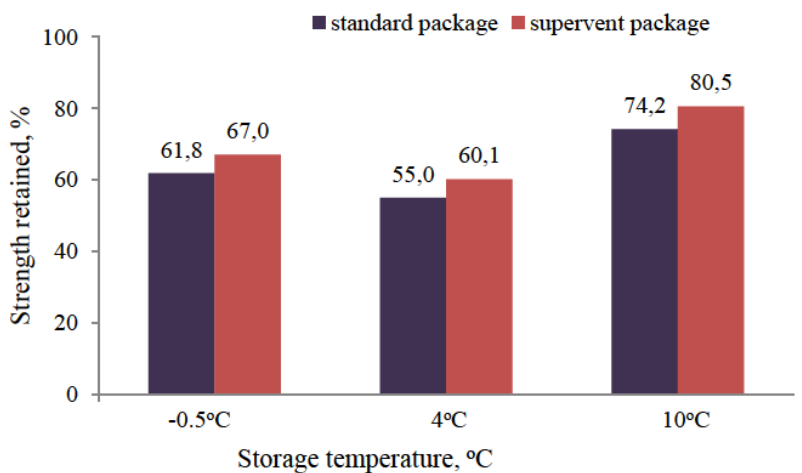

Figure 4: Package compression strength retained at different storage temperatures and $90 \% \mathrm{RH}$ compared to testing under standard (ASTM) condition $\left(23^{\circ} \mathrm{C}\right.$ and $\left.50 \% \mathrm{RH}\right)$

\subsection{Compression strength of corrugated packages}

Figure 4 compared the compressive strength of 'Supervent and Standard' packages exposed to different storage conditions for 48 hours. After 48 hours the strength of standard package at storage temperature $4^{\circ} \mathrm{C}$ remained at $55.0 \%$ while that of those exposed to $-0.5^{\circ} \mathrm{C}$ at $61.8 \%$. From our experiments the moisture content of 'Supervent' package increased to $11.4 \%$ and maintained its maximum compressive load at $60.1 \%$. When the packages stored in the storage temperature at $10^{\circ} \mathrm{C}$, resulted moisture content $6.7 \%$ and its maximum compressive strength reduced to $19.5 \%$ after 48 hour storage. However in 'Standard' packaging the compression strength was reduced to $25.8 \%$ at $10^{\circ} \mathrm{C}$ storage temperature. According to literature report, as corrugated package moisture content increased from $7.7 \%$ to $16.4 \%$, compressive strength reduces by $52 \%$ [11]. Storage temperature between 10 and $4{ }^{\circ} \mathrm{C}$ had significant influence on package compression strength $(P<0.05)$. However, storing below $4^{\circ} \mathrm{C}$ did not result in significant changes in compression strength for both packaging designs. BCT is a function of moisture content as compression strength distinctly decreases with the ascending of moisture content.
The compression strength decreased $167 \mathrm{~N}$ and $219 \mathrm{~N}$ per moisture content percent for supervent and standard packaging respectively from standard storage condition to $4^{\circ} \mathrm{C}$ storage. 'Standard' package lost $45 \%$ (from $9244.4 \mathrm{~N}$ to $5086.2 \mathrm{~N}$ ) of their compressive strength by being exposed $4^{\circ} \mathrm{C}$ storage temperature whereas 'Supervent' package lost $33 \%$ (from 7966.7 to $4791.2 \mathrm{~N}$ ). Moisture content increased by $39.3 \%$ (Standard) and 33.4\% (Supervent) for $4^{\circ} \mathrm{C}$ storage temperature. The decrease of BCT values was almost linear with respect to the moisture content upto $4^{\circ} \mathrm{C}$ storage. As the increasing moisture content of the components have soften the lignin matrix between the cellulose microfibrils of the wood fibres and affects its mechanical property [5]. Static compression strength of moulded paper tray was significantly affected by moisture absorbed or dissipated and decreased with increased moisture [27]. The compression strength of paper based packaging material is generally affected by moisture content of the packaging material directly influenced by the environmental conditions [8]. As a result, the influence of moisture content should be concerned when predicting the strength of corrugated packaging. The main impact of package design on optimisation of the fresh produce is to maintain mechanical integrity and improve cooling performance. An optimal package design with respect to mechanical integrity is not necessarily the best with respect to cooling performance and fruit quality. The mechanical performance of the Standard package was clearly better than Supervent package.

\subsection{Corrugated package deformation}

Package deformation is a measure of how much a box is compressed at the end of a test [28]. Compression strength values of packages commonly include the deflection at failure or at the end of a specific load application. Under compression testing corrugated packaging displays buckling after deformation. Package deformation under different storage temperature has been shown in Table 2. Both package designs showed the deformation $1.41 \mathrm{~cm}$ for maxi- 
mum compression strength at standard ASTM storage condition. Storage temperature has non significant influence on deformation $(P>0.05)$. In the range of $6 \%-11 \%$ moisture content of the packages tested under the investigated storage conditions, the displacement was in the range of 1.27 to $1.49 \mathrm{~cm}$. In the current work, the displacement was not significantly $(P>0.05)$ affected by the moisture content of the boxes (Figure 5). Paunonen and Gregersen [29] studied the effect of moisture content (range of $2 \%-11 \%$ ) on deformation and found that the displacement was constant $(10 \mathrm{~mm})$. The authors concluded that failure criterion for corrugated packaging in compression can be based on vertical displacement, and this is independent of moisture content.

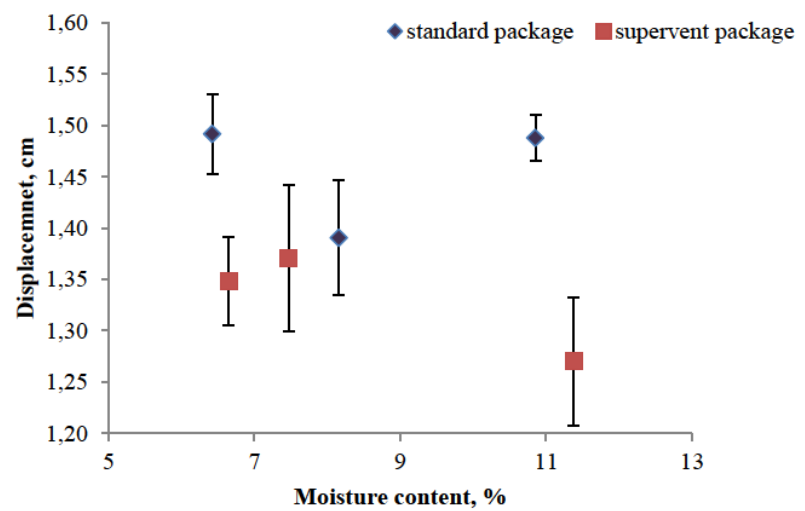

Figure 5: Effect of moisture content on displacement of packaging at maximum compression strength

\section{Conclusions}

In this investigation, the effects of storage temperature on the moisture content and compression strength of packaging designs used in the citrus industry were investigated. Storage temperature had significant effect on moisture content of both package designs. The increase in moisture content reduced the compression strength. Maximum compression strength reduction was found at $4^{\circ} \mathrm{C}$ storage temperature. Maximum deformation does not depend on moisture content of the packaging material. Compression strength of the 'Supervent' packaging which had $34 \%$ more vent area was significantly lower than that of the 'Standard' packaging design. Quantifications of corrugated package moisture content and distributions under various desirable and undesirable conditions are needed, which can then be related to mechanical failures in real world conditions. A proper package selection minimises the produce damage, thereby ensuring a quality product for users.

Acknowledgement: This work is based upon research supported by the South African Research Chairs Initiative of the Department of Science and Technology and National Research Foundation. The financial support of the South African Postharvest Innovation Programme (PHI-2) and Hortgro ${ }^{\text {Science }}$ through the award of a project on "Packaging of the Future" is gratefully acknowledged.

\section{References}

[1] Castro (de) L, Vigneault C, Cortez L. Effect of container openings and airflow rate on energy required for forced-air cooling of horticultural produce. Canadian Biosystem Engineering 2005,21,3.1-3.9.

[2] Thompson J, Mejia D, Singh R. Energy use of commercial forced-air coolers for fruit. Applied Engineering in Agriculture 2010,26(5),919-924.

[3] Pathare PB, Opara UL, Vigneault C, Delele MA, Al-Said FA-J. Design of packaging vents for cooling fresh horticultural produce. Food and Bioprocess Technology 2012,5(6),2031-2045.

[4] Singh J, Olsen E, Singh S, Manley J, Wallace F. The effect of ventilation and hand holes on loss of compression strength in corrugated boxes. Journal of Applied Packaging Research 2008,2(4),227-238.

[5] Navaranjan N, Dickson A, Paltakari J, Ilmonen K. Humidity effect on compressive deformation and failure of recycled and virgin layered corrugated paperboard structures. Composites Part B: Engineering 2013,45(1),965-971.

[6] Biancolini M, Brutti C, Porziani S. Corrugated board containers design methods. International Journal of Computational Materials Science and Surface Engineering 2010,3(2),143-163.

[7] Markström H. Testing Methods and Instruments for Corrugated Board: A Handbook. Lorentzen \& Wettre; 1999.

[8] Fadiji T, Coetzee C, Opara UL. Compression strength of ventilated corrugated paperboard packages: Numerical modelling, experimental validation and effects of vent geometric design. Biosystems Engineering 2016,151,231-247.

[9] Dongmei W, Huxiang G, Ziyou B. Effect investigation of relative humidity and temperature on multi-layer corrugated sandwich structures. Journal of Sandwich Structures and Materials 2013,15(2),156-167.

[10] Hägglund R, Carlsson L. Packaging performance. In: Niskanen K, editor. Mechanics of Paper Products. Berlin: De Gruyter; 2011.

[11] Zhang Y-I, Chen J, Wu Y. Analysis on hazard factors of the use of corrugated carton in packaging low-temperature yogurt during logistics. Procedia Environmental Sciences 2011,10,968-973.

[12] Hung DV, Nakano Y, Tanaka F, Hamanaka D, Uchino T. Preserving the strength of corrugated cardboard under high humidity condition using nano-sized mists. Composites Science and Technology 2010,70(14),2123-2127. 
[13] Pathare PB, Opara UL. Structural design of corrugated boxes for horticultural produce: A review. Biosystems Engineering 2014,125,128-140.

[14] Marcondes J. Cushioning properties of corrugated fiberboard and the effects of moisture content. Transactions of the ASAE 1992,35(6),1949-1953.

[15] Koning Jr J, Stern R. Long-term creep in corrugated fiberboard containers. Tappi Journal 1977,60(12),128-131.

[16] Patterson J. Material reduction in corrugated containers for the fresh produce industry. Project report, Industrial Technology, Orfalea College of Business, USA, 2011.

[17] Pathare PB, Berry TM, Opara UL. Changes in moisture content and compression strength during storage of ventilated corrugated packaging used for handling apples. Packaging Research 2016,1(1),1-6.

[18] Ferrua M, Singh R. Modeling the forced-air cooling process of fresh strawberry packages, Part I: Numerical model. International Journal of Refrigeration 2009,32(2),335-348.

[19] Ngcobo ME, Delele MA, Opara UL, Zietsman C), Meyer C). Resistance to airflow and cooling patterns through multi-scale packaging of table grapes. International Journal of Refrigeration 2012,35(2),445-452.

[20] Delele MA, Ngcobo MEK, Getahun ST, Chen L, Mellmann J, Opara UL. Studying airflow and heat transfer characteristics of a horticultural produce packaging system using a 3-D CFD model. Part I: Model development and validation. Postharvest Biology and Technology 2013,86,536-545.

[21] Defraeye T, Lambrecht R, Tsige AA, Delele MA, Opara UL, Cronjé $P$, Verboven $P$, Nicolai B. Forced-convective cooling of citrus fruit: Package design. Journal of Food Engineering 2013,118(1),8-18.
[22] Zou Q, Opara LU, McKibbin R. A CFD modeling system for airflow and heat transfer in ventilated packaging for fresh foods: I. Initial analysis and development of mathematical models. Journal of Food Engineering 2006,77(4),1037-1047.

[23] Delele MA, Ngcobo MEK, Opara UL, Pathare PB. CFD modelling to study the effects of table grape packaging and stacking on fruit cooling and moisture loss. Acta Hortic

[24] Csavajda P, Böröcz P, Mojzes Á, Molnár B. The effect of creasing lines on the compression strength of adjustable height corrugated boxes. Journal of Applied Packaging Research 2017,9(1),3.

[25] Jinkarn T, Boonchu P, Bao-Ban S. Effect of carrying slots on the compressive strength of corrugated board panels. Kasetsart Journal: Natural Science 2006,40(6),154-161.

[26] Wang D-M, Wang J, Liao Q-H. Investigation of mechanical property for paper honeycomb sandwich composite under different temperature and relative humidity. Journal of Reinforced Plastics and Composites 2013.

[27] Sørensen G, Hoffmann J. Moisture sorption in moulded fibre trays and effect on static compression strength. Packaging Technology and science 2003,16(4),159-169.

[28] Singh J, Bainbridge P, Singh S, Olsen E. Variability in Compression Strength and Deflection of Corrugated Containers as a Function of Positioning, Operators, and Climatic Conditions. Journal of Applied Packaging Research 2007,2(2),89-102.

[29] Paunonen S, Gregersen $\varnothing$. The effect of moisture content on compression strength of boxes made of solid fiberboard with polyethylene coating. Journal of Applied Packaging Research 2010,4(4),223-242. 